Publisher policy allows this work to be made available in this repository. Published in International Journal of Action Research by Verlag Barbara Bundrich. The original publication is available at: https://www.budrich-journals.de/index.php/ijar/article/view/34506

International Journal of Action Research, (2019) 3, 217-236.

\author{
From silos to inter-professional collaboration-
}

\title{
A mixed methods case study utilizing participating action research to foster multidisciplinary teams in a day care surgery department
}

\author{
Gunhild Bjaalid, Rune Todnem By, Bernard Burnes, Aslaug Mikkelsen \\ and Olaug Øygaarden
}

\begin{abstract}
This single case study reports on the establishment of a multidisciplinary day care surgery at a Norwegian University Hospital utilizing participating action research design principles drawn from the socio-technical theory. Data was collected through mixed methods including stakeholder analysis, document studies, observations of meetings, semi-structured interviews and participating group methods. The senior management at the hospital had decided to implement a department that diverged from organizing around professional disciplines, and this decision evoked strong resistance among several professional groups in the first phases of this project. This case follows the implications of the decision to establish a multidisciplinary day care surgery through reorganizing location, staff and management structures. The findings suggest that the hospital achieved the vision of creating an efficient multidisciplinary work environment, reducing the culture of tribalism between professions, and creating a work environment with a high degree of knowledge transfer. This case describes how action research can be used to reduce organizational silos and to improve multidisciplinary cooperation.
\end{abstract}

Key words: Action research, Day care surgery, Hospital organization, Organizational change, Socio-technical design, Interprofessional teams, Patient-based organization

\section{Resumen}

\section{Introduction}

Health-care inflation due to rising costs is worrying Europe's politicians. Standardization of treatment and the development of patient pathways, reduction of hospitalization and increasing day care or polyclinic treatments, are all examples of organizational changes with a goal to increase efficiency and reduce costs (Lapsley, 2008).

Within this context, a Norwegian University Hospital (NUH) sat out to improve its elective day care surgery department (DCS) provision through establishing a new and multidisciplinary patient-centered department with a focus on how different healthcare professions interact in a greater degree than what is traditionally the case, and to provide patients with the best possible treatment (Saha, Beach \& Cooper, 2008). The hospital management had patient related goals such as more flexible patient care, organize services around patient groups, increase numbers of satisfied patients and operations, and on top of that, increase employee satisfaction through the development of a multidisciplinary department.

This article reports on the establishment of the DCS through its first 18 months of operation. The purpose was to explore if participatory action research design principles inspired by the socio-technical system approach, could facilitate organizational change and help overcome resistance and conflicts in establishing the new multidisciplinary patient-centered DCS department.

The following research questions were explored:

1) How can the use of participating action research design principles drawn from the Socio-Technical System Approach be utilized to prevent and overcome conflicts when establishing a patient-centered multidisciplinary day care surgery department? 
2) How can the use of participating action research design principles drawn from the Socio-Technical System Approach be utilized to obtain a good work environment with an efficient task planning that can facilitate ambitious operational goals?

\section{Organization Development and the Socio-Technical Systems Theory}

One of the earliest forms of Organization Development (OD) is the socio-technical systems approach developed by the Tavistock Institute in the UK (Burnes, 2014). This approach assumes that to successfully change or improve a system firsthand information about the organization it sits within is required and this can only be achieved through empirical observations and detailed concrete descriptions of work tasks and work role relationships (du Guy \& Vikkelsøy, 2012). Therefore, action research is very much in line with the socio-technical focus on addressing significant problems working with organizational members, rather than simply studying them.

Emery $(1969,1978)$ defined technical systems to include a wide range of technology and materials such as unit operations and centrality of operations, the spatial layout and the physical work setting along with productivity and quality of the work as a whole. The social systems include tasks, task interdependency, occupational roles and grouping of roles into teams, how work tasks were coordinated and controlled, the effectiveness of production, the delegation of responsibilities, and the degree of reliance on the expertise of workers in making complex judgments and decisions. Furthermore, Emery (1978) defined three socio-technical system design principles:

First, the best design for a productive system is the one in which each part of the system embodies the goals of the overall system. Second, the system should be self-managing to the point that the work groups have the autonomy to cope with their problems by arranging their own use of resources. This second design principle has proven to be the most important principle in distinguishing the socio-technical system's paradigm from other approaches to work design (Pasmore, 1995). Third, the best design will be the one that recruits and develops its constituent parts so that they have the intrinsic properties suited to the demands of the position they occupy. At a basic level, this third principle would indicate the need to design jobs with a degree of multi-skilling, but at a more sophisticated level, it implies that account must be taken of the human potentialities for reasoning, creativity and leadership that might be expected in any group of human beings (Emery, 1978).

A central tenet of the socio-technical approach is that behaviour is shaped by the work group to which an individual belongs. Therefore, rather than seeking to change the behaviour of each individual worker, one should seek to change the behaviour of the work group, which is what one might expect from a system perspective (Burnes, 2014). The socio-technical approach also found that job satisfaction and productivity increased when jobs were designed to comprise 'variety, task completeness and above all autonomy' (Wall et al. 1984, p. 15).

Without a clear sense of what the organization's core tasks are before implementing changes, the change process is at best for nothing and at worst quite destructive according to the socio-technical approach. To neglect the specificity of circumstances in order to generalize abstract change principles to make a 'one size fit all' recipe for change processes in all types of organizations, may prevent the organization to pursue its specific purposes (du Guy \& Vikkelsøy, 2012).

Having this is mind, Cherns's (1976) elaboration of socio-technical design principles - described in the following section - was not used as a cookbook recipe for a successful organizational development into a socio-technical system, but as guiding principles for the second phase of this case study. Good solutions are based on detailed descriptions. Detailed descriptions are based on close observations. The new approach in this article was that we tried to combine the socio-technical design principal with a more contemporary big group technic called 'The World Café' (Tan \& Brown, 2005). This is a modern method of creative participation very popular among organizational consultants, but not so much used as a participating action research method.

\section{The socio-technical design principles}

Focus on the interrelationship between humans and technology

A fundamental tenet of the socio-technical approach is that the design of a work system should understand the interdependence between and give equal weight to social and technical factors in order to achieve the joint optimization of the two subsystems (Cherns, 1976).

\section{Variety in work tasks and task distribution}

Ideally, employees should be allowed to perform a variety of tasks so they can become multi-skilled. Emery (1978) argued that work design should always seek for a redundancy of functions rather than a redundancy of tasks. Multi-skilled employees are better able to cope with challenges or opportunities that may arise because they can rearrange how they organize themselves and the tasks they perform.

\section{Developing decision-making ability and autonomy}


In order to test out new work arrangements, employees must be provided with responsible autonomy. In socio-technical terms, this is often referred to as the principle of 'minimal critical specification' (Herbst, 1974). That is, employees should be told what they are expected to do, (e.g. design and run an excellent day care surgery department), but not how to do it.

\section{Management structure}

In order to enable responsible autonomy and self-regulation it is important that leadership and supervision are close and internal in the operating team. Thus, socio-technical theory challenges traditional leadership theories by arguing that autocratic control leads to sub-optimal performance (Mumford, 2006).

\section{Shared goals}

According to the socio-technical approach, the best work design for a productive system is one where each part of the system embodies the goals of the overall system (Emery, 1978). In order to do this, organizational members must share the responsibility of identifying challenges and solutions. They must look for continuous improvement, which means that change should be perceived as an ongoing fluid process rather than a process with an end point. This has been named the 'principle of incompletion' (Cherns, 1976) and implies that work design is an interactive and continuous process.

\section{The World Café method}

The World Café methodology (Tan \& Brown, 2005) is a simple, effective, and flexible format for hosting large group dialogue. World Café can be modified to meet a wide variety of needs depending on the context, numbers, purpose, location and other circumstances. The main ingredients are to divide the group in numbers between 4 and 6 , and set up tables for each group with paper and pens. The facilitator should first introduce the World Café process, setting the context, sharing the Café etiquette. The facilitator can also decide to break up professional groups and power structures when he or she divides participants into groups. Each group will then visit each Café table (it can vary how many tables depending on themes and size of groups). They will have a twenty to thirty minutes round of conversation with the small group seated around a table. The discussion will be centered by a predefined theme or question on each table. When time is up, each member of the group moves to a new table with another discussion topic, except for one person who stays behind as the "table host". The host write down comments and suggestions in each group to the topic or question specially created for the specific context and desired purpose of the World Café.

After all groups have been to the different Café tables the big group is gathered together, and the different table hosts give a summary of the discussions and suggestions at each table. Individuals are also invited to share insights or other results from their conversations with the rest of the large group. These results are written down and further action decided before the World Café day ends.

\section{Methodology}

\section{Context and background}

This study was a cooperation between the local university's business school and the top management of the hospital. An important aim for the hospital management was to develop a day care surgery where different professions came together in an integrated and coordinated effort to treat a variety of pathologies in an efficient and cost effective way. The goal to develop a separate day care surgery department was not new. The process of establishing the DCS had been ongoing for several years, and since 1997, a number of attempts had failed. In 2003, the NUH had got as far as to design, fund and construct a new DCS building only to find the surgeons unwilling to relocate, or split their tasks between two locations. As a result, the new building was transferred to another department. For the hospital management this was also a small pilot for a much bigger project to come, namely building a new hospital in the area expected finished in 2023.

In April 2014, the hospital finally succeeded in opening the new DCS. The researchers collected data and participated in the project over a two-year period from October 2013 through the first 18 months after the DCS opened in April 2014.

The research approach in the first phase (the year before start-up) was initially inductive investigating empirically the action going on in the organization. In the next phase (the first year in operation), all regular employees participated in the action research approach.

\section{Research design and data collection}

This study was a single case study (Yin, 2011), following traditional qualitative methodology, which is not participatory in essence. The first year of data collection, we used traditional case study methods such as stakeholder analysis, documents studies, observations of meetings and semi-structured interviews. In the second year of the case study, we used a participatory action-oriented method inspired by the socio-technical approach. In our case, group participation can be seen as one of the "multiple evidence sources" proposed by Yin (2011). These methods differ from the more traditional functionalist and positivist ways of thinking.

First, the researchers conducted a stakeholder analysis and analyzed all formal documents in the case. This involved 190 pages of project documents including goals, risk analysis and planning documents, internal information newsletters, e-mail exchanges and written notes from project meetings. At this time observation in the project- and steering groups established to work with the project, was also conducted. This observation started up the last year before formal start-up, the frequency for 
these meetings was an average of two to three meetings per month. Fieldsnotes were written after these observations by the first author. Then followed the first phase of interviews.

In-depth interviews with eight key stakeholders were carried out. All hospital departments influenced by the new daycare surgery at the hospital had employees participating in either the steering group or a project group. All interviews were semi-structured interviews taken at the hospital and recorded; they lasted up to 75 minutes. All professions (nurses, physicians, hospital leaders and administrative personnel) were included in these interviews.

After the initial round of data collection, the second phase of this case study started. In this phase reflections on action for change were developed in line with the socio-technical approach, they were both an inspiration for developing the changes, and a framework for analyzing the data. This work started before the formal start-up of the day care surgery and lasted throughout the first 18 months in operation. The focus in this phase was working together with all the leaders and regular employees at the new day care surgery to generate practical solutions for how they could achieve developing an outstanding day care surgery with a smooth workflow and good work environment.

In this phase, the socio-technical design principles (see page 4 and 5) were discussed and used to develop task planning and the work environment in the new DCS-department.

Then followed a new round of in-depth interviews with nine regular employees at the DCS, as well as five interviews with the leader of the new DCS. These interviews had an action-oriented critical focus with the goal to bring forth ideas that could potentially be acted upon to improve both task planning and improvements of the work environment of the new department.

The first author of this article participated in three half-day seminars with the goal that all regular employees should suggest and discuss potentials to improve task planning and work flow, as well as the social work environment, and the interaction between these. The first author, who is a trained organizational psychologist, had the role as a facilitator and process leader of these seminars. In the very first meeting with the regular employees the first week in the new day care surgery, the formal goals of the top management and project group were presented. All of these employees had long work experience from the main hospital, but they had not worked together as a team previously. So this was a good opportunity to open a new communicative space with the group (Wicks \& Reason, 2009), in relation to both practical, emotional and power aspects. Hospitals are normally very hierarchically when it comes to power and influence; this is also natural due to strict rules and regulations on what job tasks you formally are allowed to perform due to your profession and competence. Therefore, it was a clear goal in these meetings to open a discussion were all different voices could be raised and heard.

This started a discussion among the employees around what was realistic when it came to performance goals; surprisingly some of these goals were new to the employees. Then followed a discussion on what improvements and suggestions they had when it came to organization and work flow for the new department, and what kind of work environment they wanted to create now that they had the possibility to form their new work environment from the start. It was the suggestions from the employees in this first meeting that formed the topics later discussed in 'The World Café' sessions.

This started a discussion among the employees around what was realistic when it came to performance goals; surprisingly some of these goals were new to the employees. Then followed a discussion on what improvements and suggestions they had when it came to organization and work flow for the new department, and what kind of work environment they wanted to create now that they had the possibility to form their new work environment from the start. It was the suggestions from the employees in this first meeting that formed the topics later discussed in 'The World Cafe' sessions.

The goal was to facilitate the group process to encourage reflective observations in line with participating action research as a method focusing on developing workable solutions to practitioners' problems. In the session before formal start-up and in the next five months, both theoretical and empirical knowledge were introduced in the seminars to challenge participants' assumptions regarding their own practice and to start a discussion on what type of work organization and work environment they wanted to create. In these sessions, we were drawing on elements from both the pragmatic and the critical action research orientation (Johansson \& Lindhult, 2008). After five months, all employees participated in 'The World Cafe' method (Tan \& Brown, 2005). The focus was now on the following three themes: 'The work environment', 'Efficiency and procedures', and 'How can we improve task planning and work flow in the future?' The Café was run as a combination of an organizational development process and participating research design (Reason \& Bradbury, 2001). The main aim of these seminars was to ensure not only reflective, but also practical action (Jansen, Baur, de Wit, Wilbrink \& Abma, 2015) and to let the employees of the DCS-department define and formulate both problems and solutions to improve patient treatment, work flow and the psychosocial work environment. The time between the seminars focused on trying out these actions in practice and evaluate if they worked in accordance to plans and intentions. In accordance to other action research designs the change implementation method was cyclical, in the sense that implementing changes are derived from the findings and will be tested in subsequent action research (e.g. Acosta, Goltz \& Goodson, 2015). All of the change suggestions were written down in the seminars and different groups of employees were given responsibility to work on implementations of suggestions in the timeframe between meetings, normally it was a couple of weeks in-between meetings. Some suggestions were so called "low hanging fruits", easy and uncontroversial suggestions that everyone agreed on (e.g. put a number on the chair the patients wait in so you know which patients are where, or put all patients ready for operation and cleared by the surgeon in one area). Other suggestions needed thorough discussions between the medical personnel (e.g how young patients are suitable for day care surgery). Some suggestions were more controversial and created tension in the group, like moving nurses around in pre and post-operational positions to make the surgery less vulnerable when employees were absent from work, in this way forcing them out of their regular work responsibilities and comfort zones.

The socio-technical design principles and the World Café method also include some common normative goals scholars using participating action research in healthcare seem to share. Hooks (2006) identified these as summative partnership attributes focusing on power and decision-making sharing, autonomy for patients and employees, shared knowledge, participation, communication and professional competence. 


\section{Participants}

The informants in the first phase of the study, were chosen after a stakeholder analysis and came from all relevant hospital departments affected by the new DCS, and from all administrative departments having a role in the process. Informants were selected based on their organizational positions, making sure that those especially relevant to the project were interviewed following due ethical procedures. In the second phase, it included all regular employees.

Table 1 in here. Overview over the phases, goals, data collection and participating action research in this study.

\section{Interview guide}

Standardized semi-structured interviews were utilized to produce comparable data, and all hospital documents and written reports from the project meetings in the pre start-up phase were studied. The main goals from the written documents were implemented in the interview guide. The interviews took place in the participants' normal work environment, and the interview guide consisted of open-ended questions, and were adapted to each situation and participant.

\section{Data analysis}

First, a preliminary analysis of the data noting key issues was undertaken, the resistance and time it took to establish the new department, and the difficulties in organizing different professions under a new common management structure stood out as themes to analyze further in the first phase of the case study. Second, an analysis guided by theoretical perspectives was performed (Giola \& Chittipeddi, 1991).

All text in the interviews containing information about establishing the DCS according to the research questions, were coded. The next step was first-order analysis of the selected data. Through this process, an account of events based on the dominant themes expressed by the research participants, was put together, and it was possible to look for patterns in these events and in the participants' accounts (Gioia \& Chittipeddi, 1991). This strategy involves constructing a detailed story from the raw data, which was done in order to prepare an analytical chronology, clarifying sequences across levels of analysis and establishing preliminary analytical themes (Pettigrew, 1990). In order to discover the themes and patterns in the first order analysis, techniques such as categorization, abstraction and comparison were used (Spiggle, 1994).

\section{Trustworthiness}

In this study, a range of strategies were used both to avoid analyzing the data prematurely and to avoid other data interpretation flaws. First, the data was collected systematically over a long period of time (over two years) and then two independent researchers interpreted the data and developed first and second order categories based on the themes of interest. The incoming data was organized around certain topics, themes and central questions. The data was examined to see how it fitted the expected categories, and categorized into different tables and groupings of similar topics.

The experts working on this case (leaders, project leaders or employees at the DCS and the hospital) were used to participate both as informants in interviews, and to read through and validate, criticize or comment the researchers' analysis.

\section{Findings and Discussion}

\section{Key events and changes}

In establishing the DCS, some major issues had to be addressed. In the first phase of this study, senior management had to identify and overcome resistance among other stakeholders over the proposal to establish the DCS in a new building separate from the existing hospital with permanent employees from different professions located under a new management structure. This was seen as especially difficult as the employees involved were united in their opposition to the move away, both from the hospital and from their traditional management structure. A force field analysis was used as a method to gain a greater understanding of the changes required in order to achieve establishing a service-based DCS. The findings suggested that existing traditional and learned boundaries between professional groups and different stakeholder perspectives made the process of bringing all groups into one department under one manager something of a challenge (Øygaarden et al., 2018), a challenge that was not solved since both the surgeons and part of the anesthesia personnel ended up coming to the DCS as temporary personnel.

The second phase of this study involved discussing and deciding on all the details of how the DCS should operate including the type of equipment, the layout of the new facility, which medical and other professions should permanently be employed on site, what services should be provided from the hospital, and DCS's new management structure. One of the main challenges in this phase was whether and how to involve temporary employees who would be based at the existing hospital in the management of the DCS. 
Table 2 in here: Coding of issues in the process of establishing a day care surgery

\section{Preventing and Overcoming Resistance}

The decision to establish the new DCS in a separate building outside the hospital with a new management structure was expected to have both negative and positive effects on employees. At the hospital, the surgeons were able to do other, unrelated work tasks in between the surgeries. It is hard to achieve a good workflow when all personnel had so many work tasks outside the operation theatre and no common ground to discuss the workflow. Some interviewees saw this as counterproductive:

'Between surgeries, the surgeons run around doing all sorts of work tasks. I am sure that it is very important and useful tasks they are doing. In the meantime, the rest of the surgical team is ready for the next surgery. We are ready to put the patient to sleep. Therefore, we call on the operators, and they do not answer or the calling system does not work, and then you get a delay. That is not good for anyone.... So the way I see it the question is: what is the most appropriate way to organize this? Having operators present so they can continuously operate, operate and operate...or, should they run around doing everything else at the same time?' (NUH anaesthesiologist)

However, others, both senior management and physicians expressed a different view, arguing that multitasking was important:

'Unfortunately, we do not have enough specialists in all disciplines, which leads to physicians doing more than one task at a time. In a department located outside the hospital area, they cannot do that. At the hospital they can run in to the post or to the clinic and do work tasks in-between. Ideally, this is not the best way to organize it. However, it is better than cancelling or patients having to wait all day for a doctor...' (NUH senior management team member)

To involve already hard-pressed specialists was a time-consuming but necessary process in order to avoid the same fate as two previous attempts to establish a day care surgery, which both failed. These groups undertook a long process of discussing and deciding on topics such as type of surgeries to be included in the DCS; which patients were best suited for day care operations; the finances; the goal setting; and the location of the new department.

\section{Focus on the interrelationship between humans and technology}

Freedman (2013) noted that a socio-technical system comprises two separate but interdependent systems, i.e. the human beings who perform the work, and the technological system that is composed of the tools, techniques, and methods required to allow people to accomplish specific tasks. In an operating theatre with several medical and nursing specialties serving the same patient with high complexity in both work tasks and equipment, the interrelationship between the two systems is especially evident (Rydenfält, Larsson \& Odenrick, 2017). To have an efficient workflow in a day care surgery, the physical surroundings play an essential role. Early on in the new DCS initiative, experienced day care surgery staff were asked to participate in drawing up the outlines of how they would like to develop the physical surroundings to support a seamless workflow. It was experienced day care surgical staff's idea to create the department as a circle where patients move around in a natural order from phase to phase. The experts were allowed to come up with their suggestions before the building of the new DCS:

'... the good thing in this project is the involvement of the staff. They have decided where all the lockers will be placed. All the doors. All the walls. Therefore, they are responsible for the choices they have made, and that is why they believe it is the right choices. Because these are competent people with extensive experience.' (NUH senior management team member)

\section{Variety in work tasks and task distribution}

One of the guiding principles of socio-technical approach, according to Emery (1978), is to seek for a redundancy of functions rather than redundancy of tasks. After one year in operation, the regular staff in the new DCS reported experiencing much higher levels of job tasks variety than expected. This development was due to the introduction of new patient groups not previously planned for, and a lower number of staff, with the implication of everyone having to step outside of their old professional roles and learn new work tasks. The goal in this action research project was to allow staff to participate in implementing the multidisciplinary DCS by giving them a high degree of competence and excellence in day care surgery as a field, and hence developing this as a specialty:

'All surgical nurses know what they are meant to do in the operating theatre. However, the day care surgery field involves much more than that. Day care surgery is all the pre-operative and post-operative competences seen under one.' (DCS nurse)

In order to ensure that DCS staff obtained pre- and postoperative work experience in support of competence transfer and development, all staff participated in an internship scheme. Before opening the DCS, there was a concern from different professions that working with day care surgery would provide too little variety in work tasks and therefore reduce competence development. In practice, DCS staff reported the opposite: 
'My old colleagues at the hospital said that they thought it was going to be too boring for me in a day care surgery. Too little action, challenge and drama. However, in reality we have such a variation in patient groups, diagnoses and work tasks. In addition, we have a different responsibility here and have to trust in our own abilities that we can handle everything ourselves.' (DCS anaesthesia nurse)

The possibility to discuss work procedures and practice with colleges with a range of different specialties facilitated the improvement of multidisciplinary teams and knowledge transfer, as well as the possibility to utilize the knowledge in everyday work practice.

\section{Shared goals}

According to the socio-technical approach, the best work design for a productive system is one where each part of the system embodies the goals of the overall system (Emery, 1978). The DCS initiative had two main goals. The first goal was to develop an efficient patient-centered day care surgery department with an outstanding work environment for the employees:

'We have always had a vision in this project of creating a working environment characterized by inter-disciplinary teamwork and ownership ... that all employees should experience ownership for the department and responsibility for the DCSdepartment being as good as possible.' (NUH senior management team member)

The second goal was that the initiative had to specify efficiency in numbers of operations per year. Whilst the first goal was fairly straightforward and uncontroversial, this second goal was perceived to be more controversial, especially among the medical department managers delivering services to the DCS. However, it was a conscious choice from the NUH senior management team to have ambitious goals:

'We had an absolutely absurd start-up plan to be honest. It was a deliberate choice, because I wanted full pressure from day one, without any slack. The patient focus and the focus on no cancellations of planned operations... is one of the most valuable elements in the work culture at this hospital. For all of us it is a shame... it's a shame every time we have to cancel operations.' (NUH senior management team member)

At the project meetings senior managers of the different surgeon-groups constantly repeated that they did not have enough operators, or in some cases even patients to fill the numbers of operations and operation days set for DCS in the first year. There was no immediate solution to this disagreement, which kept emerging in meetings and discussions. Not surprisingly, this theme evolved into a problem in the DCS start-up phase, and certain types of operations had to be rescheduled due to some departments not managing to fill their operation theatres.

The new DCS did not manage to reach the target of expected numbers of operations per year during the first year in operation. When it comes to efficiency of the new DCS the senior managers at the hospital insisted that a target of 4000 operations per year was achievable, even though staff in both the project and steering groups challenged this. This is not an unusual occurrence; senior managers often feel that they need to over-promise in order to justify investing in new facilities (Burnes, 2014)

Although it requires some time to establish a good workflow within any new department, the target set was perceived to be extremely ambitious, and even with full capacity in all five operation theatres from day one it was perceived as hard to reach. Furthermore, some medical fields were lacking operators, and staff reported from an early stage that they would not manage to deliver according to plan due to this. Finding the patient groups suitable for day care operations also took some time, but after one full year in operation, all five operation theatres were now in use every day.

\section{Decision-making ability and autonomy}

Socio-technical theory was pioneering for its shift in emphasis towards considering teams or groups as the primary unit of analysis and not the individual. Sociotechnical theory pays particular attention to internal supervision and leadership at the level of the "group" and refers to it as 'responsible autonomy'. Staff must be provided with responsible autonomy to test new solutions. This is referred to as the principle of Minimal Critical Specification, which simply means that people should be told what to do, but not how to do it (Herbst, 1974). To follow this design principle is also in line with the action research principle of working with people and seeing them as experts, not simply studying them (Bradbury \& Reason, 2003).

The NUH senior management team had a clear vision that DCS staff should be allowed to participate actively in shaping the task planning, workflow and work environment in the new department:

'What we gave them was the opportunity to create their own work place, work culture and work procedures. What we wanted in return was top quality. Best challenge you can give competent people if you ask me...' (NUH senior management team member)

This research involved a high degree of staff participation. They had three half-day seminars with different relevant themes with the aims to improve both work environment and work flow. In these seminars, all staff participated, and it was designed to work out practical solutions to perceived challenges. This could be anything from developing standardized patient procedures to better ways of organizing the storage room. Staff worked out suggestions on how to solve both large and small problems potentially occurring in the DCS. They undertook evaluations of how and where patient flow typically stopped up (e.g surgeons forgetting to tell the rest of the staff that a patient is examined and ready for operation, and as a result, they are waiting too long in the hallway instead of getting ready for operation) and set out to solve these problems. When they discovered 
barriers in the workflow, they were encouraged to find ways of removing these. Because of the relatively flat structure and small size of the department, it was easy to try out new solutions on an ongoing basis:

'I knew straight away that I've now got a completely different ownership to my new workplace. I am not just one of many pieces in a puzzle. Here I am allowed to be involved in the design of the work tasks and procedures. That has been a new experience for me, and it feels really good.' (DCS anaesthesia nurse)

Several staff reported it was a new and welcomed experience not only to be encouraged and allowed to provide input to the organization of the department, but to observe that their input was actually used in new procedures.

Staff focused on the positive effect closer relationships between professions and specialists have on operational duties, and how these closer relationships could lead to more knowledge and competence transfer across disciplines:

'We cooperate so well under operations now, also with the physicians, we are smooth operators...Because we know each other, we know each other so well now that we are really like ... a team. It is completely different, the feeling of identity. It is good to feel such an identity to your work...' (DCS nurse)

The findings suggest that the NUH senior management team achieved part of their vision of creating more interdisciplinary teams in the new DCS. Furthermore, they had only one lunchroom in the new DCS, at the hospital all the different professions have separate lunchrooms:

'I have worked as an anaesthesia nurse for almost thirty years up at the hospital, and I have never had lunch with surgeons or orthopedists before moving down here [to the new DCS]. I think it is nice that we can sit down with them and talk about everyday life stuff... Because we all eat together, not only the regular ones. We include the temporary staff as well, and share our lunch with them if they forget to bring their own food. I think most of them find it enjoyable and relaxing here.' (DCS anaesthesia nurse)

Staff were proud of their new department, and what they had achieved in a very short period of time:

'I must say that to be allowed to create your own work culture as we had the opportunity to do in this department, has been fantastic.' (DCS nurse)

The feedback from the patients after the first year was generally positive and the DCS had no serious incidents regarding patient safety. Some patients reported that they felt "a bit like they were parts on a conveyor belt", but most reported that they liked being able to go home as soon as possible after their operation.

The staff also reported being motivated by the positive patient responses:

'One of our patients woke up after operation and said this is the best private hospital I have ever been to!' (DCS nurse)

In order to create true multidisciplinary teams where all staff help to develop each other's skills, the feeling of "being in the same boat", was important:

'I like to see the patients coming and know that we can follow them through the process. We can give them safety and competence. And at the end of the day we can see the colour returning to their faces. That is my motivation.' (DCS anaesthesia nurse)

\section{Management and team structure}

According to the socio-technical design, in order to enable responsible autonomy and self-regulation, it is important that management and supervision are close and internal in the operating team. NUH senior management had a vision of creating a new team and management structure at the DCS-department. They realized this was going to be difficult if the majority of staff were 'just visiting' and if the new DCS did not have one senior manager. It was clear from early on in the planning process that operators would not be part of the regular staff at the new department. Instead, the managers of the different hospital surgery departments would provide surgeons in a shift system:

'Everyone agreed that if this new department was to succeed it was important to have regular staff feeling ownership of the results, and a local manager of the department. The problem was; no one wanted to report to this manager, they all wanted to keep their manager at the hospital.' (NUH senior management team member)

When it came to task planning and task distribution, study informants reported the high degree of temporary (shifting) staff as challenging:

'The DCS-department must have a seamless workflow to be efficient, the

more people you are depending on contributing, the harder it is to achieve this goal. If you get new people constantly that do not know the standard routines or where things are put on top of tough deadlines to reach the goals, I think shifting staff will be a challenge'.

(DCS anaesthesiologist) 
The goal of having as many regular staff as possible reporting to a local senior manager, and thereby creating a focused and stable work force with stronger teams was only partly met the first year in operation:

'The challenge with health organizations is the discipline based silo organization, where the patient flow needs to cross those borders to be efficient. So many people might think that we did not manage to solve this issue in the new DCS given the fact that many of the staff are still being provided by the individual hospital departments. However, in reality we have come very far in a new way of organizing our services in this department, because we have managed to create a department that includes all professions, except physicians.' (NUH senior management team member)

The establishment of the new DCS challenged the typical hospital organization because different professions from different departments were required to cooperate under one new 'umbrella'. Hence, a new management structure had to be established.

The operating theatre is a dynamic, high-pressured environment, with different specialists working together to ensure a successful outcome for the patients. This complex system relies on the performance of the individual team members, and is vulnerable to errors and adverse events (Undre, Sevdalis, Healey \& Darzi, 2007). To challenge the hierarchies and professional silos, and have a work environment where all staff work towards delivering together working in teams where people know each other, is important. This is very much in line with the socio-technical approach to work with the group as a system to make improvements, not with individual workers (Herbst, 1974).

\section{Concluding remarks}

The research provided mixed results: whilst managers and staff were satisfied with the autonomy determining the physical surroundings, work tasks, work flow and work environment in the new DCS, how to manage temporary (on loan) versus regular staff and the ability to set their own operation goals and program stayed an unresolved issue. As regards the positive outcomes in relation to task planning, workflow, DCS staff highlighted the ability to influence important decisions, democratic leadership-style, practical locations and the possibility of socializing with all staff regardless of their profession or specialism, as an important success factor in achieving the vison of a good work environment. Building down silos and creating multidisciplinary teams require belonging to the same management structure and the possibilities to discuss work related issues and improvements together.

The socio-technical approach stresses that an effective and efficient work place requires an optimal interrelationship between humans and technology; it requires that all staff have task variety, decision-making ability and autonomy; it stresses the importance of shared goals, and a management structure that supports all of these. Crucial to achieving this is the ability of all employees to participate in the design of the new system. In this case, it was only the regular employees in the DCS who participated in the action research approach. One of the main criticism of hospital changes based on NPM reforms is the lack of influence and participation from clinical and first-line personnel in the change processes (Slagstad, 2017). The combination of socio-technical change principles (Cherns, 1976) and the World Café (Tan \& Brown, 2005) approach gives a good framework for allowing creative participation from employees in a range of different professions and positions, allowing them to discuss changes and improvements in their work environment regardless of their position in the power hierarchy. These methods seem to prevent turf battels and allow cooperation to reach a shared goal.

Our findings suggest that the possibility to discuss work tasks, procedures and practice with colleges from a range of different specialities facilitated the improvement of inter-professional knowledge transfer, as well as the possibility to utilize the knowledge in everyday work practice. Staff at the DCS reported on new ways of working together as a team, even comparing themselves to a "well-oiled machine" with a higher degree of competence transfer in this new organization.

One weakness of this case was that an important profession in any day care surgery, namely the surgeons, did not move to the new DCS. It was clear early in phase one of this case, that they would not be permanently positioned in the new DCS. This was due to several factors such as the type of operations available in a day care surgery compared to a general surgery department, and it was due to lack of specialists in many fields and a resistance to move out of the hospital and the management structure they were used to belong to.

So the vision of building down the professional silos and create permanent inter-professional teams, with both the surgeons and parts of the anaesthesia staff still being 'on loan' from the main hospital, was only partly achieved in this case. These two professions tended to see themselves as being part of the mother departments at the hospital rather than part of the DCS.

However, after some months of operation, several of the temporary personnel from the hospital, being surgeons or nurses, became more regular. Since some preferred to be at the DCS they choose to come more often. Therefore, the problem of having many temporary and new employees not knowing the routines and colleagues became a smaller issue than first expected in phase 1.

This study of the establishment of the new DCS shows that it is possible to develop a cooperative, democratic and multidisciplinary work environment that optimizes the workflow and abilities with the potential of the technology of work to produce a system that meets the needs of staff and patients. However, it does not happen by accident or mere goodwill. It requires an approach to change that recognizes the need to optimize the social and technical systems of the workplace. It also needs an participating approach that involves all staff from relevant professions in the design process, managers and nonmanagers alike.

However, as the DCS study has shown, not everything will be perfect from the word go. Organization design and operation are on-going processes, which staff need to keep working with. Seen in that light, the DCS has made remarkable progress. 


\section{Acknowledgements}

We acknowledge the participation of the regional health authorities, the hospitals and the university in this project.

Disclosure Statement

The authors reported no potential conflict of interest.

\section{Bibliography}

Acosta, S., Goltz, H., \& Goodson, P. (2015). Autoethnography in action research for health education practitioners. Action Research, 13(4), 412-428.

Bradbury, H., \& Reason, P. (2003). Action research: An opportunity for revitalizing research purpose and practices. Qualitative social work, 2(2), 155-175.

Burnes, B., \& Cooke, B. (2012). Review article: The past, present and future of organization development: Taking the long view. Human Relations, 65(11), 1395-1429.

Burnes, B. (2014) Managing Change (6th Edition). Pearson: Harlow.

Cherns, A. (1976). The Principles of Sociotechnical Design. Human Relations, 29(8), 783-792.

du Gay, P., \& Vikkels $\varnothing$, S. (2012). Reflections: On the lost specification of 'change'. Journal of Change Management, 12(2), 121-143.

Emery, F. E. (1978). Systems thinking. New York: Penguin.

Emery, F.E. (1978). The assembly line: its logic and our future. International Studies of Management \& Organization, 82-100.

Emery, F. E., \& Trist, E. L. (1969). The causal texture of organizational environments. Systems thinking, 1, 245-262.

Freedman, A. M. (2013). The Application of Systems Theory to Organizational Diagnosis. The Wiley-Blackwell Handbook of the Psychology of Leadership, Change, and Organizational Development, 405-441.

Gayá Wicks, P. \& Reason, P (2009). Initiating action research: Challenges and paradoxes of opening communicative space. Action Research, 7 (2), 243-260.

Gioia, D. A., \& Chittipeddi, K. (1991). Sensemaking and sensegiving in strategic change initiation. Strategic management journal, 12(6), 433-448.

Herbst, P. G. (1974). Socio-technical design. London: Tavistock Publication.

Jansen, E., Baur, V., de Wit, M., Wilbrink, N., \& Abma, T. (2015). Co-designing collaboration: Using a partnership framework for shered policymaking in geriatric networks. Action Research, 13(1), 65-83.

Johansson, A, W., \& Lindhult, E. (2008).Emancipation or workability? Critical versus pragmatic scientific orientation in action research. Action Research, 6(1), 95-114.

Lapsley, I. (2008). The NPM agenda: back to the future. Financial accountability \& management, 24(1), 77-96.

Mumford, E. (2006). The story of socio-technical design: reflections on its successes, failures and potential. Information Systems Journal, 16(4), 317-342.

Olsson, E \& Lau, M. (2015). When one size does not fit all: Using participatory action research to co-create preventive healthcare services. Action Research, 13(1), 9-29.

Pasmore, W. A. (1995). Social science transformed: the socio-technical perspective. Human Relations, 48(1), 1-21.

Pettigrew, A. M. (1990). Longitudinal field research on change: Theory and practice. Organization science, 1(3), $267-292$.

Reason, P., \& Bradbury, H. (2001). Handbook of action research: Participative inquire and practice. London: Sage Publication.

Rydenfält, C., Larsson, P. A., \& Odenrick, P. (2017). An action-oriented method for interprofessional organization development at a hospital operating unit. Action Research, 15(2), 177-197.

Saha, S., Beach, M. C., \& Cooper, L. A. (2008). Patient centeredness, cultural competence and healthcare quality. Journal of the National Medical Association, 100(11), 1275.

Spiggle, S. (1994). Analysis and interpretation of qualitative data in consumer research. Journal of consumer research, 491503.

Tan, S., \& Brown, J. (2005). The world café in Singapore: Creating a learning culture through dialogue. The Journal of Applied Behavioral Science, 41(1), 83-90.

Todnem By, R. (2005). Organisational change management: A critical review. Journal of change management, 5(4), 369-380.

Trist, E. L., \& Bamforth, K. W. (1951). Some social and psychological consequences of the Longwall Method of coal-getting: An examination of the psychological situation and defences of a work group in relation to the social structure and technological content of the work system. Human relations, 4(1), 3-38.

Undre, S., Sevdalis, N., Healey, A. N., Darzi, S. A. and Vincent, C. A. (2006). Teamwork in the operating theatre: cohesion or confusion? Journal of evaluation in clinical practice, 12(2), 182-189.

Wall, T. D., Burnes, B., Clegg, C. W. and Kemp, N. J. (1984). New technology, old jobs. Work and People, 10 (2), $15-21$. 
Yin, R. K. (2011). Applications of case study research. Thousand Oaks: Sage.

Øygaarden, O., Bye, R, T., Bjaalid, G. \& Mikkelsen, A. (2019) Establishing a multidisciplinary day-care surgery department: Challenges for nursing management. Journal of Nursing Management, 12(1), 133-142. 
Table 1: Overview of the phases, data collection, goals and participating action research in this case study.

\begin{tabular}{|c|c|c|c|}
\hline & \multicolumn{2}{|l|}{ PHASE 1} & PHASE 2 \\
\hline Timeframe & \multicolumn{2}{|l|}{$2009-2013$} & $2014-2016$ \\
\hline 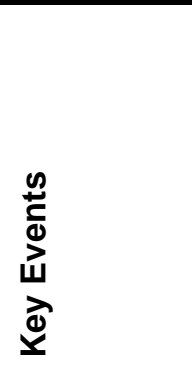 & \multicolumn{2}{|c|}{$\begin{array}{l}\text { Project aimed at moving surgical patients from hospitalization to day care treatments } \\
\text { starts. } \\
\text { The project group recommends a new, externally located department, initiating Phase } \\
1 \text { of the project. } \\
\text { Project re-assessed, foundational documents drawn up defining activities, location, } \\
\text { staffing and financing for the new DCS-department. } \\
\text { Project Manager hired, detailed consultations and planning with professional groups } \\
\text { begin. }\end{array}$} & $\begin{array}{l}\text { A multidisciplinary day c } \\
\text { opened in April } 2014 \text { out }\end{array}$ \\
\hline \multirow{4}{*}{ 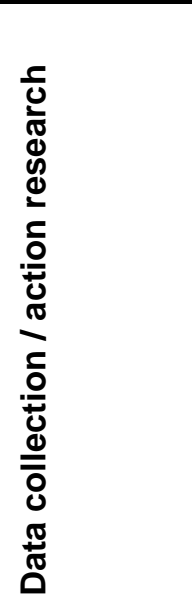 } & \multicolumn{2}{|c|}{$\begin{array}{l}\text { Document analysis } \\
\text { Including all types of informative documents about the project, } \\
\text { reports from meetings, risk assessments reports, and goal-setting } \\
\text { documents from top management (October 2013). }\end{array}$} & $\begin{array}{l}\text { Participating intervie } \\
\text { with } 9 \text { regular employe } \\
\text { Five in-depth action-o } \\
\text { department at different } \\
\text { Interviews with the other } \\
\text { anesthesia nurses) in the }\end{array}$ \\
\hline & \multicolumn{2}{|c|}{$\begin{array}{l}\text { Stakeholder analysis } \\
\text { A stakeholder analysis was performed and representatives for all stakeholders were } \\
\text { interviewed. (autumn 2013). }\end{array}$} & $\begin{array}{l}\text { Three half-day seminar } \\
\text { collection, but also part o } \\
\text { and work environment in } \\
\text { Five months after start-ur } \\
\text { (April to September } 2014\end{array}$ \\
\hline & \multicolumn{2}{|c|}{ In-depth interviews with 8 key stakeholders (autumn /winter 2013). } & Implementing of sugges \\
\hline & \multicolumn{2}{|c|}{ Observation in project and steering groups (autumn / winter 2013). } & Evaluation of the proje \\
\hline \multirow[b]{2}{*}{$\frac{n}{\overparen{0}}$} & $\begin{array}{l}\text { Obtain detailed, concrete, pract } \\
\text { equipment, personnel and opere }\end{array}$ & $\begin{array}{l}\text { ions of tasks, task planning, } \\
\text { d in the new DCS-department. }\end{array}$ & $\begin{array}{l}\text { Establish a patient-cente } \\
\text { per year }\end{array}$ \\
\hline & \multicolumn{2}{|c|}{$\begin{array}{l}\text { Overcome resistance among staff to move out of the hospital and establish } \\
\text { a new management structure. }\end{array}$} & $\begin{array}{l}\text { Establish a good multidi: } \\
\text { improved operational teal }\end{array}$ \\
\hline \multirow{2}{*}{ 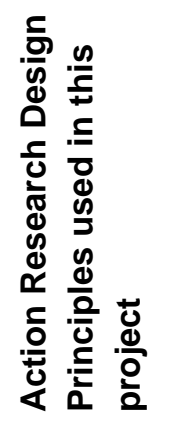 } & $\begin{array}{l}\text { Interrelationship } \\
\text { humans and } \\
\text { technoloov }\end{array}$ & $\begin{array}{l}\text { New } \\
\text { management } \\
\text { and team }\end{array}$ & $\begin{array}{l}\text { Descion-making } \\
\text { autonomy }\end{array}$ \\
\hline & \multicolumn{3}{|c|}{ Develop Shared Coals } \\
\hline
\end{tabular}


Table 2 Coding of issues in the process of establishing a day care surgery

\begin{tabular}{|c|c|c|}
\hline & Second-order themes & $\begin{array}{l}\text { Aggregate dimensions } \\
\text { The socio-technical design } \\
\text { principles }\end{array}$ \\
\hline $\begin{array}{l}\text { Physicians did not want to } \\
\text { move out of hospital because it } \\
\text { would restrict their work } \\
\text { flexibility (e.g. to do other work } \\
\text { tasks between operations) } \\
\text { Patient safety issues } \\
\text { Physicians under specialization } \\
\text { or with lack of experience } \\
\text { cannot be sent alone down to } \\
\text { the new department so it will } \\
\text { increase the need for } \\
\text { specialized personnel } \\
\text { Some employees were worried } \\
\text { about high efficiency goals and } \\
\text { repetitive work task in a day } \\
\text { care surgery } \\
\text { More "blood, action and } \\
\text { challenges" in a general } \\
\text { surgery department than in a } \\
\text { day care surgery }\end{array}$ & $\begin{array}{l}\text { Resistance against external } \\
\text { location and expected negative } \\
\text { outcomes related to } \\
\text { reorganizing a day care } \\
\text { surgery outside the hospital } \\
\text { area }\end{array}$ & $\begin{array}{l}\text { Decision-making ability and } \\
\text { autonomy }\end{array}$ \\
\hline $\begin{array}{l}\text { Not enough operators available } \\
\text { to fill up operation program } \\
\text { both places simultaneously, } \\
\text { and sometimes not even } \\
\text { enough patients } \\
\text { Some patient groups are } \\
\text { organized under day care } \\
\text { surgery, but includes patients } \\
\text { that are too sick, old or young } \\
\text { to be operated in the DCS } \\
\text { department outside the hospital } \\
\text { location } \\
\text { Not having regular employees } \\
\text { in all positions in the new DCS } \\
\text { makes efficiency goals harder } \\
\text { to reach }\end{array}$ & $\begin{array}{l}\text { Objections against high } \\
\text { efficiency goals for the new } \\
\text { DCS }\end{array}$ & $\begin{array}{l}\text { Management and organizational } \\
\text { structure }\end{array}$ \\
\hline $\begin{array}{l}\text { Avoid cancellations of elective } \\
\text { surgery due to incoming } \\
\text { emergencies } \\
\text { Create new teams sharing } \\
\text { work experience, competence } \\
\text { and work tasks across } \\
\text { professions and disciplines }\end{array}$ & $\begin{array}{l}\text { Expected positive outcomes } \\
\text { related to task planning and } \\
\text { work distribution in a new DCS }\end{array}$ & Shared goals \\
\hline
\end{tabular}




\begin{tabular}{|c|c|c|}
\hline $\begin{array}{l}\text { Physicians allowed to be } \\
\text { dedicated to operations only } \\
\text { and not having to do other work } \\
\text { tasks } \\
\text { Different work hours allow } \\
\text { more efficient work flow } \\
\text { Predicable operation program } \\
\text { Be able to give the patients } \\
\text { good and efficient treatment in } \\
\text { nice and functional } \\
\text { surroundings } \\
\text { Organize professions around } \\
\text { patients } \\
\text { Develop a new inter-disciplined } \\
\text { work culture with social } \\
\text { belonging across disciplines } \\
\text { and profession Higher } \\
\text { competence transfer between } \\
\text { different professions }\end{array}$ & & Humans and technology \\
\hline $\begin{array}{l}\text { Regular employees versus } \\
\text { shifting employees } \\
\text { Unclear authority, responsibility } \\
\text { and accountability of services } \\
\text { provided to the new day care } \\
\text { surgery } \\
\text { Leadership structure (who is } \\
\text { leading who) } \\
\text { Danger of creating "A and B } \\
\text { teams" with both regular and } \\
\text { shifting personnel } \\
\text { Moving between locations } \\
\text { takes time } \\
\text { Fear of alienation from } \\
\text { profession and "mother- } \\
\text { departments" } \\
\text { Competence transfer harder } \\
\text { within your own profession }\end{array}$ & $\begin{array}{l}\text { Challenges with new } \\
\text { organization of personnel and } \\
\text { management issues }\end{array}$ & $\begin{array}{l}\text { Management structure and } \\
\text { organization of personnel }\end{array}$ \\
\hline
\end{tabular}




\section{About the authors}

Gunhild Bjaalid has a PhD with a specialization in management from the University of Stavanger Business School. She is a psychologist by profession and specializes in HRM, clinical psychology and organizational psychology.

\section{Rune Todnem By}

Professor of Organisational Behaviour (Staffordshire University Business School, UK), Professor II Change Leadership (University of Stavanger, Norway) and Co-founder and Chair of the Public Leadership Foundation. He is the Editor-in-Chief of Journal of Change Management.

\section{Bernard Burnes}

Professor of Organisational Change (Stirling Management School, UK) and is one of the leading international authorities on organisational change. Bernard is the author of over 50 journal articles, over 20 books and around 40 book chapters. His article 'Kurt Lewin and the Planned Approach to Change: A Re-appraisal' (Journal of Management Studies, 41 (6), 977 1002), received a Citation of Excellence as one of the top 50 management articles in the world in 2004, has been reprinted twice and has received over 250 citations.

\section{Aslaug Mikkelsen}

Professor at the University of Stavanger Business School. Her professional field is Strategic Management and Organizational psychology. Specializes in HRM, business strategy, and leadership studies. Her work experience includes a broad range of management positions in academic institutions and in business; she has been the Principal of the University in Stavanger a four-year period.

\section{Olaug Øygarden}

$\mathrm{PhD}$ Fellow at the University of Stavanger Business School. She has a Background from Sociology, Development Studies and Change Management. Her current field is Health Care Organizations, Hospital Management, Change Management and Project implementation.

\section{Authors' addresses}

Gunhild Bjaalid, corresponding author.

Universitetet i Stavanger

Postboks 8600 Forus

4036 Stavanger, Norway

Email: gunhild.bjaalid@uis.no

Rune Todnem By, Staffordshire University Business School, UK, Universitetet i Stavanger

Postboks 8600 Forus

4036 Stavanger, Norway

E-mail: rune.t.by@uis.no

Bernard Burnes, University of Stirling, Stirling FK9 4LA Scotland UK

E-mail: bernard.burnes@stir.ac.uk

Aslaug Mikkelsen, Universitetet i Stavanger

Postboks 8600 Forus

4036 Stavanger, Norway

E-mail: aslaug.mikkelsen@uis.no

Olaug Øygaarden, Universitetet i Stavanger

Postboks 8600 Forus

4036 Stavanger, Norway

E-mai olaug.oygarden@uis.nol: 
